\title{
RATIONALE OF CARDIOPULMONARY RESUSCITATION TRAINING AS AN ELEMENT OF MULTILEVEL EDUCATIONAL AND MOTIVATIONAL PROJECT (MEDMOTION)
}

\author{
Aldona Kubica \\ Collegium Medicum, Nicolaus Copernicus University, Torun, Poland
}

\begin{abstract}
Patients after acute coronary syndrome (ACS) are of increased risk of out-of-hospital cardiac arrest (OHCA). Therefore, education of patients' family members within the Multilevel EDucational and MOtivational intervention in patients after myocardial infarcTION (MEDMOTION) project includes practical cardiopulmonary resuscitation (CPR) skills training.
\end{abstract}

The aim of this part of the MEDMOTION project is to assess the efficacy of CPR training.

Methods The MEDMOTION project is designed as a multicenter, two-phase study with a 2-year follow-up. In phase 1 (the observational, prospective, multicentre study), patients in all centres will be treated, educated and motivated according to the current practice adopted in these centres. In phase 2 (the randomized, open-label, multicentre study), the participating centres will be randomized (1:1) to active group (multi-level educational and motivational interventions) or to control group (continuation of the previous strategy).

In the active group, the relatives cohabitating with the patient will be encouraged to participate in CPR classes and hands-on training supported with CPR dedicated MEDMOTION brochure. To convince persons emotionally close to the patient to participate in the proposed activities, we plan to conduct motivational conversations highlighting the importance of increased patient safety and family responsibility.

The analysis of CPR education and training efficacy is planned - assessment of knowledge retention and registration of CPRs outcome conducted by trained persons based on phone contact at 2 years after training.

KEY WORDS: resuscitation training, education, motivation

Disaster Emerg Med J 2020; 5(2)

\section{INTRODUCTION}

Out-of-hospital cardiac arrest (OHCA) is burdened with extremely high mortality. In the United States approximately $92 \%$ of persons who experience an OHCA event die [1, 2]. Bystander cardiopulmonary resuscitation (CPR) is pivotal for survival improvement in this critical setting; nevertheless, it is still unlikely to receive efficient and timely intervention even if OHCA events are witnessed [1,3]. Patients discharged from hospital after acute coronary syndrome (ACS) are of increased risk of OHCA comparing to the general population [4]. OHCA occurs often at home and it is witnessed by family members of the patient [5]. The CPR training of the next 
of kin of at-risk patients is thus potentially highly beneficial.

Therefore we have designed the Multilevel EDucational and MOtivational intervention in patients after myocardial infarcTION (MEDMOTION) project aimed to improve the knowledge and practical skills of not only patients after acute coronary syndrome but also their cohabitating family members. We assumed that individualized, complex health education started during hospitalisation and continued after discharge, explaining the pathophysiology and symptoms of the disease, elucidating goals and potential benefits of treatment, and highlighting the risk of premature termination of therapy, with the use of additional methods helping patients to remember the treatment schedule will enhance adherence to treatment [6]. Education of family members, in addition to the knowledge necessary to understand patients' needs and to provide them with adequate support, includes also practical CPR skills.

The project also includes a comprehensive, multistage evaluation of patients and their family members to improve the quality of medical care by personalizing educational and therapeutic interventions after ACS [7-9].

The aim of this part the MEDMOTION project is to assess the efficacy of CPR training based on British Heart Foundation course Heartstart.

\section{METHODS}

\section{Study design}

The MEDMOTION project is designed as a multicenter, two-phase study with a 2-year follow-up. In phase 1 (the observational, prospective, multicentre study), patients in all centres will be treated, educated and motivated according to a current practice adopted in these centres. The duration of phase 1 is arbitrarily assumed to be 6 months. In phase 2 (the randomized, open-label, multicentre study), the participating centres will be randomized $(1: 1)$ to:

- Active group (implementing multi-level educational and motivational interventions)

- Control group (continuing existing strategy)

The MEDMOTION project will apply multilevel, standardized, personalized educational and motivational interventions for patients after myocardial infarction and their cohabitating relatives. There are three project levels planned: Level I — in-hospital education and motivation; Level II - early post-discharge motivation (up to follow-up visit after the first year); Level III - late personalized educational and motivational activities depending on the patient needs (up to the end of the second year). To make the large-scale project feasible educational and motivational activities will be standardized using the same tools (the MEDMOTION brochures, scenarios and scales), however, all activities within the project will be personalized by using tools selected according to personal needs.

The relatives or other persons cohabitating with patient (indicated by patient) will be encouraged to participate in CPR classes and hands-on training supported with CPR dedicated MEDMOTION brochure. The CPR education program is based on the British Heart Foundation course "Heartstart" aimed to teach basic emergency life-saving skills applying six steps strategy (https://www.bhf.org.uk/how-youcan-help/how-to-save-a-life/how-to-do-cpr):

- Step 1: Shake and shout

- Step 2: Check for normal breathing

- Step 3: Call 112

- Step 4: Give 30 chest compressions

- Step 5: Give two rescue breaths

- Step 6: Repeat until an ambulance arrives

Every quarter, the 6-point CPR strategy will be reminded by email. To convince persons emotionally close to the patient to participate in the proposed activities, we plan to conduct motivational conversations highlighting the importance of increased patient safety and family responsibility.

This research is supported by the Collegium Medicum of Nicolaus Copernicus University [NCU $\mathrm{CM}$ grant for the emerging field "civilization diseases"]. The project will be registered at https:// clinicaltrials.gov and implemented after obtaining the approval of the bioethical committee.

\section{Inclusion/exclusion criteria}

The MEDMOTION project will include all consecutive patients filling the following inclusion criteria:

- hospitalization for a heart attack (STEMI or NSTEMI)

- age above 18 years

- consent to participate in the study The following exclusion criteria were defined:

- no consent to participate in the study

- incapacitated persons

- prisoners

- relatives or dependent on researchers

- mental condition preventing participation in educational and motivational activities. 


\section{Study endpoints}

The primary clinical endpoint of the MEDMOTION trial encompasses death from any cause, acute coronary syndrome, stroke, re-hospitalization for the cardiovascular cause.

The principal secondary endpoint is defined as the number of selected risk factors in which therapeutic target is achieved.

Additional secondary endpoints are defined as all selected risk factors alone and results of diagnostic scales: the Readiness for Hospital Discharge after Myocardial Infarction

Scale (RHD-MIS) [10], the Adherence in Chronic Diseases Scale (ACDS) $[11,12]$ and the Functioning in Chronic Illness Scale (FCIS) [13, 14].

A separate analysis of CPR education and training efficacy is planned - a questionnaire-based assessment of knowledge retention will be performed every year. The questionnaire contains 6 open questions referring to the six steps CPR strategy.

Moreover, registration of CPRs including clinical outcome, conducted by persons trained in MEDMOTION trial based on phone contact 2 years after training will be performed.

\section{Study population}

The interim analysis will be performed as soon as 6-month follow-up observations will be available for 1,000 patients included in phase 2 . The analysis will be carried out to calculate the final study population needed to power the study with regard to the primary endpoint. We hypothesized that enrolment of 4,000 patients (about 2,000 in each group) will be necessary.

\section{DISCUSSION}

A 30-day survival after OHCA reported in the French National Cardiac Arrest Registry was $5.11 \%$ in the absence of CPR, $8.86 \%$ with bystander's cardiac CPR and $7.35 \%$ when CPR was initiated by the Dispatch Centre $(p<0.001)$ [15]. According to the data from the Cardiac Arrest Registry to Enhance Survival (CARES) the OHCA survival rate to hospital admission was $26.3 \%$, and the overall survival rate to hospital discharge was $9.6 \%$. The overall survival in subjects who received bystander CPR was significantly higher (11.2\%) than in those who did not (7.0\%) $(p<0.001)$. Moreover, in persons who are witnessed to collapse by a bystander and found in a shockable rhythm the survival to discharge was 30.1\% [1].
It has been shown that optimised 'chain of survival' for patients with OHCA with CPR started by bystanders, police and/or first responders in $72 \%$ of patients and use of an automated external defibrillator (AED) in $63 \%$ of patients resulted in even better results with return of spontaneous circulation (ROSC) in $49 \%$ of the cases and a 1 -year-survival rate of $27 \%$ in the studied population [16].

The comparison of these data proves that there are huge opportunities for improvement [1, 16], however, adequate practical training and education including previously reported concerns and fears related to performing bystander CPR (mainly recognition of cardiac arrest, causing additional harm and lack of skills) is necessary $[15,17-19]$.

Training of family members of patients at risk for sudden cardiac death in basic life support (BLS) has been shown to be useful, as their baseline skills were poor [20]. Moreover, CPR hands-on training improved participants' skill retention and confidence to perform a BLS $[19,21-23]$. These observations confirm the desirability of our decision to include CPR training of patients' family members into the MEDMOTION project.

In the study published by Schmid et al. [19] 74\% participants declared that they would perform CPR on an adult stranger, however, only 55\% stated that they would "likely" participate in a CPR training. Previous CPR training (OR: $2.6 ; 95 \% \mathrm{Cl}, 1.6-4.3)$ and a prior witnessed cardiac arrest (OR: 2.0; 95\% Cl, 1.1-3.5) were associated with CPR class enrollment [19].

Motivational interventions are an integral part of the MEDMOTION project $[24,25]$. Sense of security and family responsibility were previously identified as motivations producing high-engagement behaviours of family members to learn CPR [26-28]. Therefore, to improve the participation of family members in CPR training we planned to apply motivation interventions that meet the needs of family members. Such a targeted intervention may be an effective training strategy to improve bystander CPR rates [29-31]. We believe that training relatives of patients after ACS will prove to be particularly valuable and effective because the probability of practical application of acquired BLS skills is particularly high.

Conflict of interest: I declare no conflict of interest.

\section{REFERENCES:}

1. McNally $B$, Robb R, Mehta M, et al. Centers for Disease Control and Prevention. Out-of-hospital cardiac arrest surveillance --- Cardiac 
Arrest Registry to Enhance Survival (CARES), United States, October 1, 2005--December 31, 2010. MMWR Surveill Summ. 2011; 60(8): 1-19, indexed in Pubmed: 21796098.

2. Szczerbinski S, Ratajczak J, Lach P, et al. Epidemiology and chronobiology of out-of-hospital cardiac arrest in a subpopulation of southern Poland: A two-year observation. Cardiol J. 2020; 27(1): 16-24, doi: 10.5603/CJ.a2018.0025, indexed in Pubmed: 29611174.

3. Ratajczak J, Łach P, Szczerbiński S, et al. Atmospheric conditions and the occurrence of out-of-hospital cardiac arrest in Poland - preliminary analysis of poorly understood phenomena. Medical Research Journal. 2018; 3(3): 121-126, doi: 10.5603/mrj.a2018.0019.

4. Kubica A, Kochman W, Bogdan M. Aleksandra Jurek, Ewa Olejarczyk, Przemysław Magielski, Marek Koziński, Grzegorz Grześk, Rajmund Wilczek, Adam Sukiennik, Elżbieta Grześk, Aleksander Araszkiewicz. The influence of undergone percutaneous coronary interventions, and earlier hospitalizations with myocardial infarction on the level of knowledge and the effectiveness of health education in patients with myocardial infarction. Advances in Interventional Cardiology. 2009; 5: 25-30.

5. Cariou G, Pelaccia T. Are they trained? Prevalence, motivations and barriers to CPR training among cohabitants of patients with a coronary disease. Intern Emerg Med. 2017; 12(6): 845-852, doi: 10.1007/ s11739-016-1493-8, indexed in Pubmed: 27350627.

6. Kubica A, Gruchała M, Jaguszewski M, et al. Adherence to treatment - a pivotal issue in long-term treatment of patients with cardiovascular diseases. An expert standpoint. Medical Research Journal. 2018; 2(4): 123-127, doi: 10.5603/mrj.2017.0016.

7. Kubica A, Obońska K, Fabiszak T, et al. Adherence to antiplatelet treatment with P2Y12 receptor inhibitors. Is there anything we can do to improve it? A systematic review of randomized trials. Curr Med Res Opin. 2016; 32(8): 1441-1451, doi: 10.1080/03007995.2016.1182901, indexed in Pubmed: 27112628.

8. Kubica A, Kasprzak M, Obońska K, et al. Discrepancies in assessment of adherence to antiplatelet treatment after myocardial infarction. Pharmacology. 2015; 95(1-2): 50-58, doi: 10.1159/000371392, indexed in Pubmed: 25592409.

9. Kubica A, Kasprzak M, Siller-Matula J, et al. Time-related changes in determinants of antiplatelet effect of clopidogrel in patients after myocardial infarction. Eur J Pharmacol. 2014; 742: 47-54, doi: 10.1016/j. ejphar.2014.08.009, indexed in Pubmed: 25199965.

10. Buszko K, Kosobucka A, Michalski $P$, et al. The readiness for hospital discharge of patients after acute myocardial infarction: a new self-reported questionnaire. Medical Research Journal. 2017; 2(1): 20-28, doi: 10.5603/mrj.2017.0004.

11. Buszko K, Obońska K, Michalski $P$, et al. The Adherence Scale in Chronic Diseases (ASCD). The power of knowledge: the key to successful patient - health care provider cooperation. Medical Research Journal. 2016; 1(1): 37-42, doi: 10.5603/mrj.2016.0006.

12. Kubica A, Kosobucka A, Michalski $P$, et al. The Adherence in Chronic Diseases Scale — a new tool to monitor implementation of a treatment plan. Folia Cardiol. 2017; 12: 19-26, doi: 10.5603/FC.2016.0000.
13. Buszko K, Pietrzykowski $\measuredangle$, Michalski $P$, et al. Validation of the Functioning in Chronic Illness Scale (FCIS). Medical Research Journal. 2018; 3(2): 63-69, doi: 10.5603/mrj.2018.0011.

14. Kubica A. Self-reported questionnaires for a comprehensive assessment of patients after acute coronary syndrome. Medical Research Journal. 2019; 4(2): 106-109, doi: 10.5603/mrj.a2019.0021.

15. Noel $L$, Jaeger $D$, Baert $V$, et al. GR-RéAC. Effect of bystander CPR initiated by a dispatch centre following out-of-hospital cardiac arrest on 30-day survival: Adjusted results from the French National Cardiac Arrest Registry. Resuscitation. 2019; 144: 91-98, doi: 10.1016/j. resuscitation.2019.08.032, indexed in Pubmed: 31499101.

16. de Visser M, Bosch J, Bootsma $M$, et al. An observational study on survival rates of patients with out-of-hospital cardiac arrest in the Netherlands after improving the 'chain of survival'. BMJ Open. 2019; 9(7): e029254, doi: 10.1136/bmjopen-2019-029254, indexed in Pubmed: 31266839.

17. Becker TK, Gul SS, Cohen SA, et al. Florida Cardiac Arrest Resource Team. Public perception towards bystander cardiopulmonary resuscitation. Emerg Med J. 2019; 36(11): 660-665, doi: 10.1136/ emermed-2018-208234, indexed in Pubmed: 31473603.

18. Jarrah S, Judeh M, AbuRuz ME. Evaluation of public awareness, knowledge and attitudes towards basic life support: a cross-sectional study. BMC Emerg Med. 2018; 18(1): 37, doi: 10.1186/s12873-0180190-5, indexed in Pubmed: 30373529.

19. Schmid KM, Mould-Millman NK, Hammes A, et al. Barriers and Facilitators to Community CPR Education in San José, Costa Rica. Prehosp Disaster Med. 2016; 31(5): 509-515, doi: 10.1017/ S1049023X16000777, indexed in Pubmed: 27491645.

20. González-Salvado V, Abelairas-Gómez C, Gude F, et al. Targeting relatives: Impact of a cardiac rehabilitation programme including basic life support training on their skills and attitudes. Eur J Prev Cardiol. 2019; 26(8): 795-805, doi: 10.1177/2047487319830190, indexed in Pubmed: 30776898.

21. González-Salvado V, Abelairas-Gómez C, Peña-Gil C, et al. Basic life support training into cardiac rehabilitation programs: $A$ chance to give back. A community intervention controlled manikin study. Resuscitation. 2018; 127: 14-20, doi: 10.1016/j.resuscitation.2018.03.018, indexed in Pubmed: 29545137.

22. Gonzï Lez-Salvado V, Abelairas-Gï Mez C, Peï A-Gil C, et al. A community intervention study on patients' resuscitation and defibrillation quality after embedded training in a cardiac rehabilitation program. Health Educ Res. 2019; 34(3): 289-299, doi: 10.1093/her/cyz002, indexed in Pubmed: 30753449.

23. Han KSu, Lee JiS, Kim SuJ, et al. Targeted cardiopulmonary resuscitation training focused on the family members of high-risk patients at a regional medical center: A comparison between family members of high-risk and no-risk patients. Ulus Travma Acil Cerrahi Derg. 2018; 24(3): 224-233, doi: 10.5505/tjtes.2017.01493, indexed in Pubmed: 29786817.

24. Kubica A, Kosobucka A, Fabiszak T, et al. Assessment of adherence to medication in patients after myocardial infarction treated with percutaneous coronary intervention. Is there a place for newself-reported 
questionnaires? Curr Med Res Opin. 2019; 35(2): 341-349, doi: 10.1080/03007995.2018.1510385, indexed in Pubmed: 30091642.

25. Kosobucka A, Michalski P, Pietrzykowski $\iota$, et al. Adherence to treatment assessed with the Adherence in Chronic Diseases Scale in patients after myocardial infarction. Patient Prefer Adherence. 2018; 12: 333-340, doi: 10.2147/PPA.S150435, indexed in Pubmed: 29551891.

26. Michalski P, Kosobucka A, Pietrzykowski $Ł$, et al. Knowledge and learning preferences of patients with myocardial infarction. Medical Research Journal. 2017; 1(4): 120-124, doi: 10.5603/mrj.2016.0022.

27. Yue $P$, Zhu $Z$, Wang $Y$, et al. Determining the motivations of family members to undertake cardiopulmonary resuscitation training through grounded theory. J Adv Nurs. 2019; 75(4): 834-849, doi: 10.1111/ jan.13923, indexed in Pubmed: 30536860.
28. Kubica A. Współpraca z pacjentem - podstawowy warunek skuteczności terapii w chorobie wieńcowej. Choroby Serca i Naczyń. 2009; 6: 131.

29. Michalski P, Kosobucka A, Pietrzykowski $\measuredangle$, et al. Effectiveness of therapeutic education in patients with myocardial infarction. Medical Research Journal. 2018; 2(3): 89-96, doi: 10.5603/mrj.2017.0011.

30. Michalski P, Kosobucka A, Nowik M, et al. Edukacja zdrowotna pacjentów z chorobami układu sercowo-naczyniowego. Folia Cardiologica. 2017; 11(6): 519-524, doi: 10.5603/fc.a2016.0104.

31. Kosobucka A, Kasprzak M, Michalski P, et al. Relation of the Readiness for Hospital Discharge after Myocardial Infarction Scale to socio-demographic and clinical factors. An observational study. Medical Research Journal. 2018; 3(1): 32-37, doi: 10.5603/mrj.2018.0006. 